\title{
Microbial residues as the nexus transforming inorganic carbon to organic carbon in coastal saline soils
}

\author{
Pengshuai Shao, Tian Li, Kaikai Dong, Hongjun Yang, Jingkuan Sun* \\ Shandong Key Laboratory of Eco-Environmental Science for the Yellow River Delta, Binzhou University, Binzhou 256603, China
}

\section{H I G H L I G H T S}

- SIC was higher at a low salinity of $<6 \%$, and declined with increased salinity.

- SOC and microbial residues exponentially decreased during increasing salinity.

- Microbial residues and SOC were tightly related to the variations in SIC

- Microbial residues act as the proxy converting SIC to SOC in saline lands.
GRAPHICAL ABSTRACT

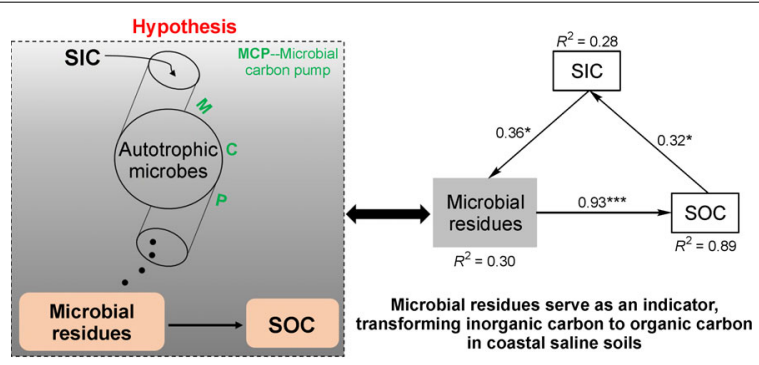

A B S T R A C T

Soil inorganic carbon (SIC), including mainly carbonate, is a key component of terrestrial soil C pool. Autotrophic microorganisms can assimilate carbonate as the main or unique $\mathrm{C}$ source, how microorganisms convert SIC to soil organic carbon (SOC) remains unclear. A systematic field survey ( $n=94$ ) was performed to evaluate the shift in soil C components (i.e., SIC, SOC, and microbial residues) along a natural salinity gradient (ranging from $0.5 \%$ to $19 \%$ ), and further to explore how microbial necromass as an indicator converting SIC into SOC in the Yellow River delta. We observed that SIC levels linearly decreased with increasing salinity, ranging from $\sim 12 \mathrm{~g} \mathrm{~kg}^{-1}$ (salinity $<6 \%$ ) to $\sim 10 \mathrm{~g} \mathrm{~kg}^{-1}$ (salinity $>6 \%$ ). Additionally, the concentrations of SOC and microbial residues exponentially decreased from salinity $<6 \%$ to salinity $>6 \%$, with the decline of $39 \%$ and $70 \%$, respectively. Microbial residues and SOC was tightly related to the variations in SIC. The structural equation model showed the causality on explanation of SOC variations with SIC through microbial residues, which can contribute $89 \%$ of the variance in SOC storage combined with SIC. Taken together, these two statistical analyses can support that microbial residues can serve as an indicator of SIC transition to SOC. This study highlights the regulation of microbial residues in SIC cycling, enhancing the role of SIC playing in $\mathrm{C}$ biogeochemical cycles and enriching organic $\mathrm{C}$ reservoirs in coastal saline soils.

() Higher Education Press 2021

\section{Introduction}

Soil inorganic carbon (SIC, mainly carbonate), usually as a "missing C sink," accounts for approximately $50 \%$ of soil C stocks globally (Mi et al., 2008; Zamanian et al., 2021) and

\footnotetext{
* Corresponding author

E-mail address: sunjingkuan@bzu.edu.cn (J. Sun)
}

essentially influences soil $\mathrm{C}$ cycles in saline-alkaline regions (Wang et al., 2019). Plant-assimilated inorganic $\mathrm{C}$ (i.e., $\mathrm{CO}_{2}$ ) is the major SOC source that atmospheric and soil-released $\mathrm{CO}_{2}$ fixed via photosynthesis contributes to the SOC pool through litter and root inputs (Fig. 1; Le Quéré et al., 2018; Huber et al., 2019). Few studies have reported that microorganisms can also utilize inorganic $C$ to maintain cell proliferation and growth (Zamanian et al., 2016; Zhu et al., 2020), whether microorganisms convert SIC to SOC remains unclear owing to the lack of a microbial indicator between SIC 
and SOC. Therefore, investigating the potential mechanisms involved in the microbially driven SIC-to-SOC transition is important in facilitating soil $\mathrm{C}$ efflux and improving soil fertility in resource-limited saline lands.

Most microbes use organic matter as energy for reproduction and growth, thus contributing to the SOC pool through microbial cell residues (Kögel-Knabner, 2017; Shao et al., 2021). However, certain microbes, e.g., autotrophic bacteria, use $\mathrm{CO}_{2}$ or carbonate as the main or unique $\mathrm{C}$ source to synthesize microbial biomass, convert SIC to SOC via biotransformation, providing organic $C$ source to soil organisms (Zamanian et al., 2016; Moore et al., 2020). For instance, ${ }^{13} \mathrm{CO}_{2}$ incubation experiments have reported that soil autotrophic microorganisms can utilize inorganic $C$ to synthesize microbial biomass (Perez and Matin, 1982; Miltner et al., 2004 ). Although living microbial biomass constitute only $2 \%-$ $4 \%$ of SOC (Dalal, 1998), rapid, iterative microbial cell growth and death generate a sizable amount of microbial necromass entombed in soils, which account for $30 \%-60 \%$ SOC in agriculture, grasslands, and forests (Liang et al., 2019). Considering the metabolic process of microorganisms in $\mathrm{C}$ transformations, Liang et al. (2017) have proposed the concept of a microbial carbon pump (MCP) to illustrate microbial processes in producing SOM via an iterative process of microbial cell uptake - biosynthesis - growthdeath, providing novel mechanistic insights into SOM formation. Such knowledge of microbial-driven $C$ in soils and the MCP concept would help to understand microorganisms converting SIC to SOC. Herein, we hypothesized microbial residues might be an indicator for inorganic $C$ transition to organic $C$ in coastal saline soils (Fig. 1).

Soil salinity is a main limiting factor for ecosystem structure and function (e.g., soil C cycle, plant type and growth, or microbial community and metabolism) in coastal saline lands spreading from the tidal flat to inland regions (Wang et al., 2011; Zhao et al., 2020a). The variation of plant type in saline conditions can play a crucial role in controlling soil $\mathrm{C}$ cycling (e.g., the transformation between SIC and SOC) through plant photosynthetic C fixation and root respiration (Chu et al., 2019; Munns et al., 2020; Zhang et al., 2021b). With the application advances of microbial necromass in soil ecology (Liang et al., 2020), the goal of our study was to investigate the relationships among soil $\mathrm{C}$ components and salinity and elucidate the mechanism underlying SIC - microbial residues - SOC along a natural salinity gradient in the Yellow River delta. We aimed to examine 1) how the concentration of SIC, SOC, and microbial residues varied along a natural salinity gradient; 2) whether SOC and microbial residues was related to SIC; 3) whether microbial residues can act as the indicator converting SIC to SOC.

\section{Methods and materials}

\subsection{Study site and sampling}

Our study areas are located in the Yellow River Delta National Nature Reserve $\left(37^{\circ} 33^{\prime}-38^{\circ} 09^{\prime} \mathrm{N}, 118^{\circ} 35^{\prime}-119^{\circ} 13^{\prime} \mathrm{E}\right.$,

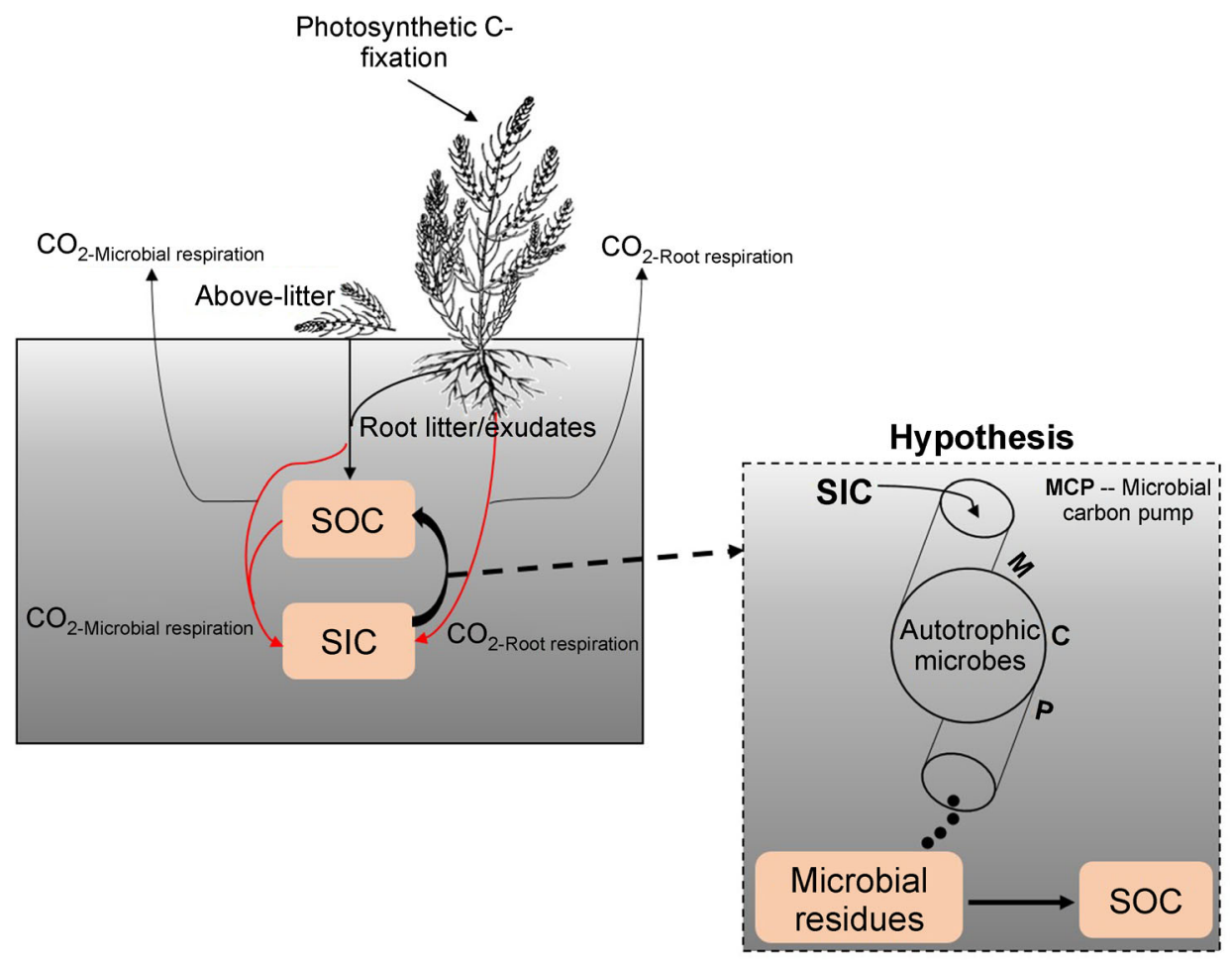

Fig. 1 Scheme of biologically driven soil organic (SOC) and inorganic carbon (SIC) cycling. SOC sources include plant litter and root exudates, whereas $\mathrm{SIC}$ sources include respired $\mathrm{CO}_{2}$ produced by microorganisms and roots (left diagram). We hypothesized that microbial residues play a role in SIC-to-SOC transition in accordance with the microbial carbon pump theory (right diagram). 
Dongying, eastern China) near the Bohai and Laizhou bays. Mean annual temperature is $12.4^{\circ} \mathrm{C}$; mean annual precipitation is $511.6 \mathrm{~mm}$ with evaporation of $1928.2 \mathrm{~mm}$. Soils are classified as Fluvo-aquic soils and solonchak originated from alluvial deposits of the Yellow River and continuous seawater intrusion, respectively. The region is dominated by crops (maize, cotton etc.) and halophyte, primarily including Phragmites, Tamarix chinensis, and Suaeda salsa.

In August 2017, we selected 94 sites of coastal saline land along a natural salinity gradient (Fig. 2; Chi et al., 2019). Five soil cores $(0-20 \mathrm{~cm})$ were randomly collected at each site using earth boring auger (diameter of $3 \mathrm{~cm}$ ), pooled, and homogenized into a representative soil sample. After removing stones, thick roots and, residues, soils were sieved to $2 \mathrm{~mm}$. Air-dried subsamples were used to analyze soil $\mathrm{pH}$, salinity, SIC, SOC, and amino sugars.

\subsection{Analyses of soil pH, salinity, SIC, and SOC}

Soil $\mathrm{pH}$ was measured by the slurry method: air-dried soils (sieved to $2 \mathrm{~mm}$ ) were stirred in water (soil:water $=1: 2.5 \mathrm{w} / \mathrm{v}$ ) for $2 \mathrm{~min}$, settling for $30 \mathrm{~min}$, subsequently measured on a pH meter. Total soluble salinity was measured by gravimetric method with water extraction (Chi et al., 2019). Carbonate levels corresponding to SIC were determined using acid-base titration (Fu et al., 2020); SOC concentration was analyzed on a Vario MACRO Cube (Elementar, Langenselbold, Germany) after removing SIC using $\mathrm{HCl}$.

\subsection{Amino sugar analysis}

Amino sugars were determined according to the protocol of Zhang and Amelung (1996). Briefly, air-dried soils (sieve to $0.15 \mathrm{~mm}$ ) were hydrolyzed using $6 \mathrm{M} \mathrm{HCl}$ at $105^{\circ} \mathrm{C}$ for $8 \mathrm{~h}$. The filtered hydrolysates were dried at $52^{\circ} \mathrm{C}$ under vacuum with a rotary evaporator. The dissolved residues using deionized water were purified by $\mathrm{KOH}$ neutralization. Residues were dissolved with absolute methanol, transferred into a vial, and dried using $\mathrm{N}_{2}$ gas at $45^{\circ} \mathrm{C}$. The dried residues were redissolved by $1 \mathrm{~mL}$ deionized water, and lyophilized. Lyophilized residues were derivatized in $300 \mu \mathrm{L}$ derivatization reagent, and subsequenly heated at $75-80^{\circ} \mathrm{C}$ for $35 \mathrm{~min}$. After cooling to room temperature, samples with $1 \mathrm{~mL}$ acetic anhydride were reheated at $75-80^{\circ} \mathrm{C}$ for $25 \mathrm{~min}$. Solutions containing $1.5 \mathrm{~mL}$ dichloromethane and $1 \mathrm{~mL} 1 \mathrm{M} \mathrm{HCl}$ were washed three times using $1 \mathrm{~mL}$ deionized water and vortexed to separate the organic phase of amino sugars. The extract amino sugars including glucosamine, galactosamine, and muramic acid, which were quantified and separated on an Agilent 7890B GC (Agilent Technologies, Santa Clara, CA,

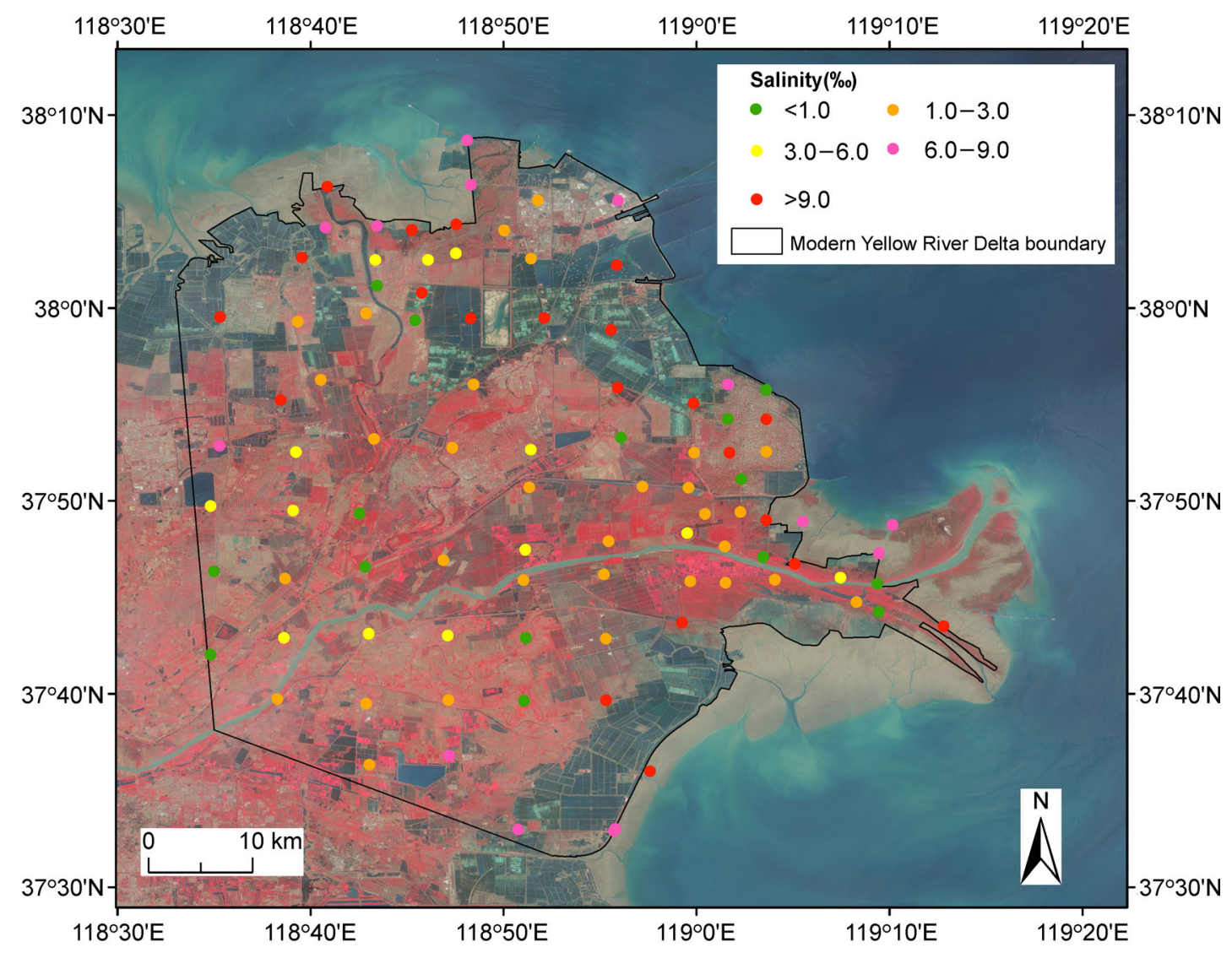

Fig. 2 Study sites along a natural salinity gradient in coastal saline lands in the Yellow River Delta. 
USA). Amino sugars, as the biomarker, were used to calculate microbial residues (Engelking et al., 2007) (detailed descriptions shown in supplementary information).

\subsection{Statistical analysis}

Generalized linear regression models with Gaussian (i.e., normal) distribution were performed to evaluate the relationships among SIC, SOC, and microbial residues ( $R$ version 3.6.0). Structural equation modeling was used to assess the relative contribution of SIC to SOC through the transition of microbial residues on AMOS software (AMOS 17.0.2 student version; Amos Development, Crawfordville, FL, USA). We used generalized least squares estimation method to fit measured data to the model. The adequate model goodness of fit was tested by root-mean-square error of approximation (RMSEA). The statistic results of indirect, direct, and total effects were selected and outputted to assess SIC effects on SOC by calculating on AMOS software.

\section{Results}

3.1 Changes in soil $\mathrm{C}$ components along a natural salinity gradient

We observed large variability in salinity concentration ranging from 0.50 to $19.24 \%$ and slight change in $\mathrm{pH}$ ranging from 7.04 to 8.08 (Fig. S1). Soil C components, including SIC, $\mathrm{SOC}$, and microbial residues, were significantly affected by salinity (Fig. 3). We found a linear decline in the concentration of SIC with increased salinity $\left(R^{2}=0.14, P<0.001\right)$ ranging from $\sim 12 \mathrm{~g} \mathrm{~kg}^{-1}$ (salinity $<6 \%$ ) to $\sim 10 \mathrm{~g} \mathrm{~kg}^{-1}$ (salinity $>6 \%$ ), despite that few low salinity soils had low SIC concentration (Fig. 3A). The concentration of SOC $\left(R^{2}=0.47, P<0.001\right.$; Fig. $3 \mathrm{~B})$ and microbial residues $\left(R^{2}=0.66, P<0.001\right.$; Fig. $\left.3 C\right)$ decreased as a power function of salinity, with the decline of $39 \%$ (SOC) and $70 \%$ (microbial residues) from salinity $<6 \%$ to salinity $>6 \%$. In addition, SOC and microbial residues showed no change as salinity $>6 \%$ (Fig. 3B, C).

Variation in soil salinity determined the distribution of vegetation type in coastal saline lands. We found that the crop (mainly maize) and Phragmites preferably grown in low salinity soils $(<6 \%)$, and Tamarix chinensis and Suaeda salsa grown in high salinity soils ( $>6 \%$ ) (Fig. S2). In addition, the difference in vegetation type induced by salinity greatly affected the concentration of SIC, SOC, and microbial residues. SIC concentration was lowest in Tamarix chinensis dominated plant community (Fig. 3D), and the maize and Phragmites held more SOC and microbial residues than Tamarix chinensis, Suaeda salsa, and mudflat (no vegetation) (Fig. 3E, F).

\subsection{Linkages among SIC, microbial residues, and SOC}

The generalized linear regression analysis demonstrated that
SIC showed the significantly positive relationship with SOC $\left(R^{2}=0.35, P<0.001\right)$ and microbial residue-C $\left(R^{2}=0.36\right.$, $P<0.001$ ) (Fig. 4).

Structural equation models revealed the low root-meansquare error of approximation (RMSEA $<0.05$ ), low chisquare $\left(x^{2}=1.35\right.$ ), low Akaike Information Criterion ( $\mathrm{AIC}=$ 251.46), and no significant variance $(P>0.05)$, which indicated that there was a strong causality among $\mathrm{SIC}$, microbial residues, and SOC (Fig. 5A). Our finding showed that SIC was tightly related to microbial residues, and accounted for $30 \%$ of the variance in microbial residues; additionally, the combination of SIC and microbial residues accounted for $89 \%$ of the variance in SOC storage (Fig. $5 \mathrm{~A}$ ). We also found that SOC could contribute $28 \%$ of the variance in SIC (Fig. 5A). Furthermore, we detected the direct and indirect effect of SIC and microbial residues on SOC (Fig. 5B). Our results found that SIC had no direct effect on SOC, whereas SIC showed the significantly indirect effect on SOC through microbial transformation (Fig. 5B).

\section{Discussion}

4.1 Driving factors of SIC shifts spanning the natural salinity gradient

In our study, we found a great changes in soil salinity, indicating that salinity might be a main factor influencing ecosystem structure and function in the coastal saline lands, such as soil $\mathrm{C}$ cycling, plant growth, or microbial metobolism (Wong et al., 2010; Cho et al., 2018; Zhang et al., 2021a). Along the natural salinity gradient, SIC was higher at low salinity $(<6 \%)$ and declined as salinity increased, suggesting that salinity stress influences SIC dynamic through the variation in soil alkalinity or biologically respired $\mathrm{CO}_{2}$ (Xie et al., 2009; Chi et al., 2018; Wang et al., 2019). SIC has two potential determinants: (1) the uptake and deposition of atmospheric $\mathrm{CO}_{2}$ by base cations (Raheb et al., 2017), and (2) the redistribution of respired $\mathrm{CO}_{2}$ to microorganisms (Moore et al., 2020). The atmospheric $\mathrm{CO}_{2}$ in regional scale is almost homogeneous, suggesting that the changed SIC should be determined by abiotic or biotic factors. Atmospheric $\mathrm{CO}_{2}$ absorption by soil base cations is dependence of soil pH, which markedly influences the magnitude of SIC (Raza et al., 2020). Particularly, acidic soil results in SIC loss, whereas saline soil increases atmospheric and soil $\mathrm{CO}_{2}$ absorption of base cations (Liu et al., 2020a; Raza et al., 2020). The slight $\mathrm{pH}$ alterations observed under different saline conditions indicated that SIC alterations cannot be attributed to regional atmospheric $\mathrm{CO}_{2}$ deposition along the nature salinity gradient.

Salinity exhibited great effects on the distribution and photosynthetic rate of maize and halophyte. Highly photosynthetic maize and Phragmites in low-salinity soil resulted in higher SIC and SOC levels than low-photosynthetic organisms of Tamarix chinensis and Suaeda salsa in high-salinity soil (Fig. S2). More new C input via plant litter and root 

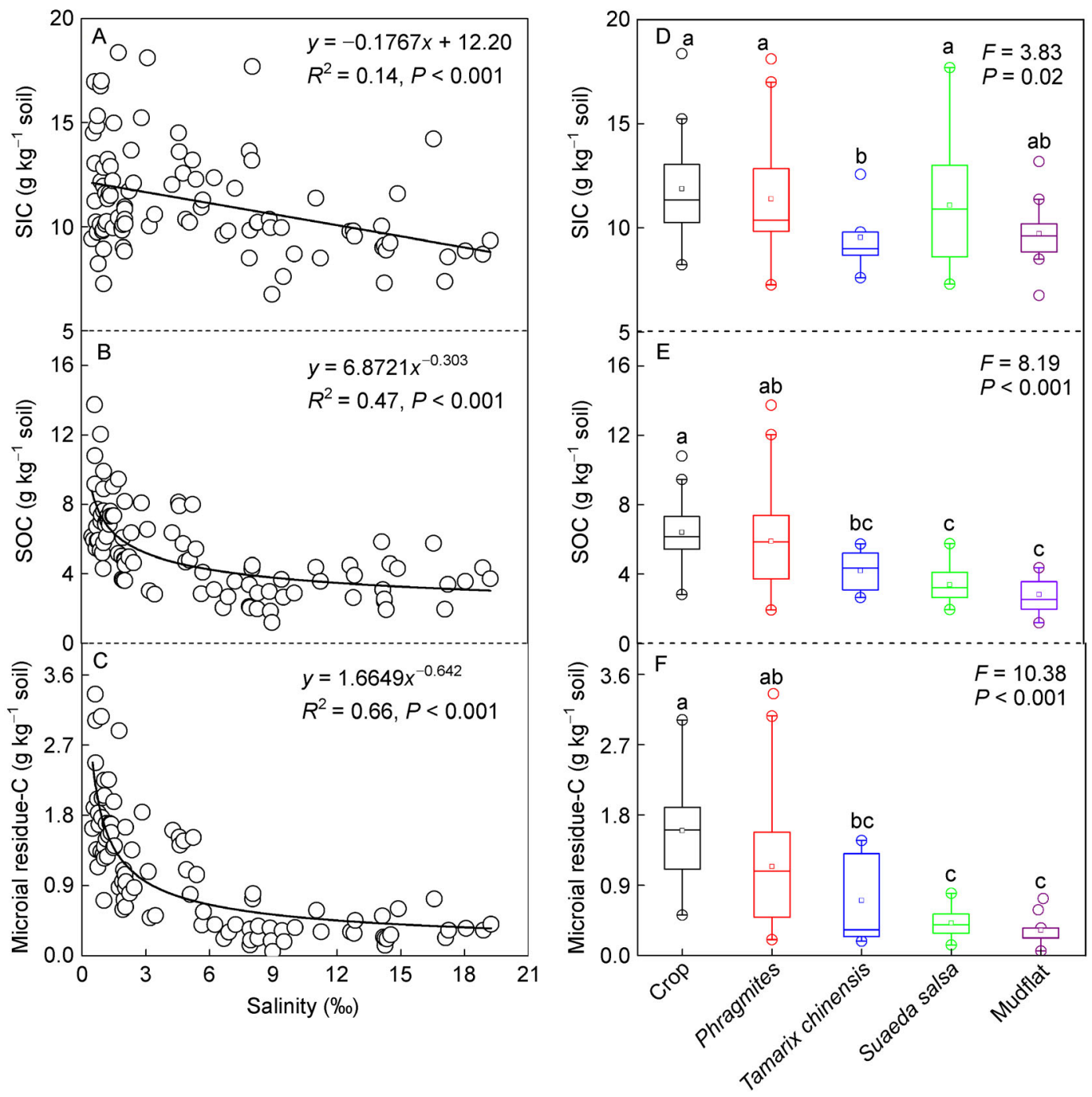

Fig. 3 Responses of SIC (A, D), SOC (B, E), and microbial residues (C, F) levels to salinity and vegetation type including crop (mainly maize, $n=21)$, Phragmites $(n=47)$, Tamarix chinensis $(n=4)$, Suaeda salsa $(n=12)$, and mudflat $(n=10)$ in the Yellow River Delta.

exudates can increase SOC accumulation and stimulate microbial activity following low salinity (Ma et al., 2017; Hessini et al., 2019); simultaneously, prime SOM decomposition to emit $\mathrm{CO}_{2}$ (Liu et al., 2020b). SOM accumulation due to improved plant communities may increase microorganismand root-respired $\mathrm{CO}_{2}$ (Fang et al., 2018; Yin et al., 2018), thus retaining $\mathrm{CO}_{2}$ (i.e., $\mathrm{SIC}$ ) via base cation absorption (Zamanian et al., 2016; Rowley et al., 2020). In our study, the structural equation models showed the direct effect of SOC on SIC, which support that SIC formation and retention in saline soils are partly originated from soil organic $\mathrm{CO}_{2}$ flux via SOM decomposition (Wang et al., 2019).

4.2 Microbial residues transforming SIC to SOC in carbonaterich saline lands

Low-salinity soil held more SOC and microbial residues, while substantially declined at high salinity of at least $6 \%$. The previous studies have pointed that plant- and microbiallyderived C primarily drive SOC storage in terrestrial ecosystems (Schmidt et al., 2011; Liang et al., 2017; Zhu et al., 2020; Angst et al., 2021). Plants (e.g, maize and Phragmites) growing in low salinity soils exhibited high photosynthetic $\mathrm{C}$ fixation could increase plant $\mathrm{C}$ into soil through litter and root exudates, thus enhancing SOC accumulation; whereas plants (e.g, Tamarix chinensis and Suaeda salsa, with low photosynthetic $C$ fixation) growing in high salinity soils resulted in the decline in SOC storage due to decreased litter and root exudates (Hessini et al., 2019; Xia et al., 2019). Additionally, soil microbial structure and functions (e.g., biomass and activity) are substantially affected by salinity (Rath et al., 2019; Zhang et al., 2021a). The previous researches have reported that low salinity soils could synthesize more microbial biomass than high salinity soils (Chen et al., 2021), which 


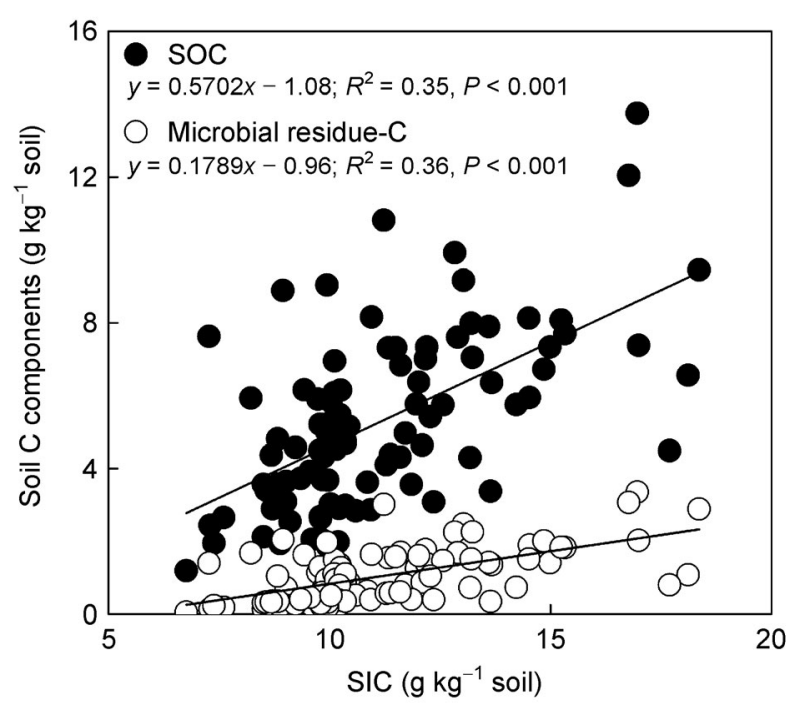

Fig. 4 Linear regression between SIC and SOC or microbial residues along a natural salinity gradient in coastal saline lands.

would inhibit the entombment of microbial residues in high salinity soils (Hu et al., 2018). Therefore, plants with high-tolow photosynthetic $\mathrm{C}$ fixation and the consistent trend between microbial residues and SOC along increasing salinity, implying that changed SOC is ascribed to plantderived $\mathrm{C}$ and microbial residue-C through litter decomposition, root exudate input, and organic matter transformation.

However, whether other soil C components, e.g., SIC accounting for $\sim 70 \%$ of soil $\mathrm{C}$ in our studied regions (Fig. 2), linking inorganic or organic biogeochemical processes are potential determinants of SOC accumulation remain unclear. The SIC not only provides $C$ source to autotrophic microorganisms (e.g., Cyanobacteria or Nitrosospira) (Moore et al., 2020; Zhu et al., 2020), but also serves as a "reserved SOM source" via bio-transformation (Miltner et al., 2004). Significant linear associations of SIC with SOC and microbial residues indicate that SIC might be a potential determinant of SOC components. Structural equation modeling further helped determine the causality and underlying mechanism of SIC-microbial residues-SOC and clarified the relative contribution of these variables to explain how SIC contribute to SOC pool. We found that SIC explained $30 \%$ of the variance in microbial residues accumulation, implying that microbial residues could be derived from SIC through autotrophic microbial biomass to necromass (Miltner et al., 2004). In addition, the variance in SOC was greatly explained by the combination of SIC and microbial residues (89\%), which indicated that SIC (indirect contribution through microbial residues transformation) and microbial residues (direct contribution) had the potential contribution to SOC storage. Taken together, these two statistical analyses supported our hypothesis that microbial residues could serve as an indicator,
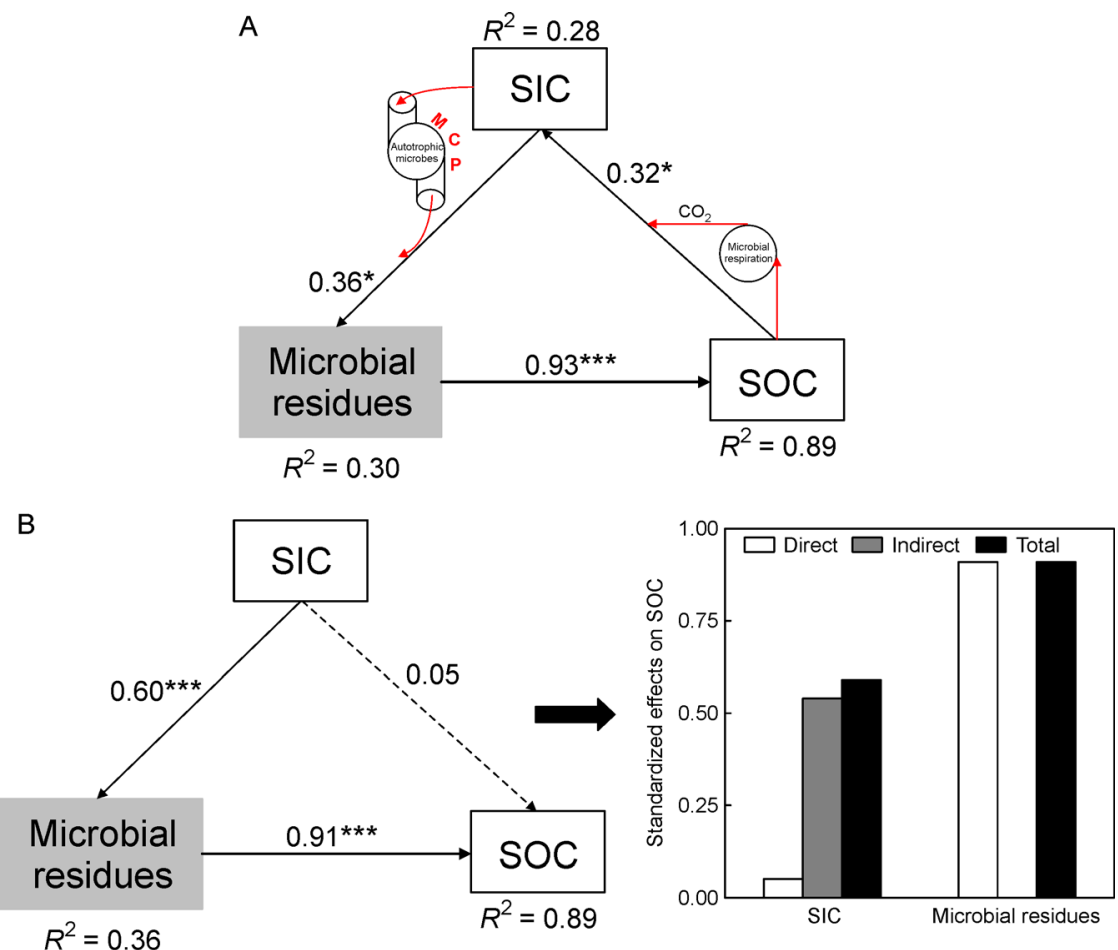

Fig. 5 A structural equation modeling examining the underlying causal relationships among SIC, microbial residues, and SOC. A, the relationships among SIC, microbial residues, and $\operatorname{SOC}\left(X^{2}=1.35, P=0.25, \mathrm{CFI}=0.98, \mathrm{AIC}=251.46, \mathrm{RSMEA}=0.007\right)$; $\mathrm{B}$, the direct and indirect effects of SIC and microbial residues on SOC $\left(X^{2}=1.07, P=0.23, \mathrm{CFI}=0.98, \mathrm{AIC}=262.09, \mathrm{RSMEA}=0.005\right)$. The direction into the arrows are orientated means the influence distribution tested. The numbers adjacent to the arrows are the standardized path coefficients $\left({ }^{\star} P<0.05,{ }^{* *} P<0.01\right.$, and $\left.{ }^{* *} P<0.001\right) ; R^{2}$ values represent the strength of explanation by independent variables. 
transforming inorganic carbon to organic carbon in coastal saline soils.

In addition, the recently proposed "microbial carbon pump (MCP)" theory provides an access to explore microbial transition of SIC to SOC (Figs. 1, 5; Liang et al., 2017). The MCP concept emphasizes the role of living soil microorganisms playing in transforming labile organic matter (including plant- and microbially-driven $\mathrm{C}$ ) to stable microbial residues, entombing in soils and contributing SOC storage and persistent (Zhu et al., 2020). Most terrestrial ecosystems, such as arable land, grassland, and forest, deposit abundant SOC, where are preferably inhabited by heterotrophic microbes using organic $\mathrm{C}$ as $\mathrm{C}$ source. However, carbonate accounts for $60 \%-80 \%$ of soil $\mathrm{C}$ in saline-alkali soil (Mi et al., 2008). Although the carbonate-rich soils are not suitable for the survival of microorganisms, autotrophic microbes (e.g., algae, cyanobacteria and lichens) can use carbonate to cell proliferation and biomass synthesis (Lian et al., 2010). Living autotrophic microbial biomass and microbial cell residues can release organic $\mathrm{C}$ and $\mathrm{N}$ via heterotrophic microbial catabolism (Lian et al., 2010); the remaining autotrophic microbial residues persist in soil through mineral associations or aggregates occlusion (Lehmann et al., 2020). Based on soil MCP concept and autotrophic microorganisms utilizing SIC, we proposed that SIC might be transformed SOC via a nexus of autotrophic microbial residues.

Despite the regulation of terrestrial $\mathrm{C}$ cycles through two microbial metabolic processes, i.e., microbial catabolismrespiratory $\mathrm{CO}_{2}$ fixed into carbonate via base cation absorption (Zhao et al., 2020b), and microbial anabolism-derived C contributes to the SOC pool (Liang, 2020). To better understand soil C cycling, our study describes microbial SIC-SOC conversion, which is important to understand the role of SIC in terrestrial ecosystem C cycling. SIC generally serves as a potential C sink (Groshans et al., 2018); however, limited information regarding its effect on terrestrial $\mathrm{C}$-energy process is available because of its long-term persistence, high stability, and limited bio-availability (Liu et al., 2020b). In this study, we explored SIC contribution to SOC pool, illustrating SIC may be converted to SOC by microbial residues, further providing extra microbial-derived $\mathrm{C}$ source for other biomes in saline soils.

\section{Outlook and conclusions}

SIC plays an important role in terrestrial $\mathrm{C}$ stocks and global $\mathrm{C}$ cycling, whereas there is lacking research on SIC, especially linked with SOC. Understanding the role of microbial necromass in SIC transition to SOC would improve soil biogeochemical C-cycling by SIC application to enrich the organic $\mathrm{C}$ reservoir in global saline soils. We believe that our work will be of great importance for regions of carbonate-rich soils. However, we did not identify the relevant microbial taxa involved in SIC transition to SOC and determine the magnitude of the SIC-to-SOC transition via microbial resi- dues. Future studies are required to investigate the molecular and metabolic processes involved in microbial SIC metabolism and assimilation using ${ }^{13} \mathrm{C}$-labeled $\mathrm{CO}_{2}$ or carbonate both in vitro and in situ.

Overall, our study found that salinity negatively affected the concentration of SIC, SOC, and microbial residues along the natural salinity gradient in coastal saline land of the Yellow River delta. We illustrated the significant associations and underlying causality among SIC, microbial residues, and SOC, verifying our hypothesis that microbial residues can serve as a nexus for transforming inorganic carbon to organic carbon in coastal saline soils. We recommend that future earth $\mathrm{C}$ modeling studies should consider both SIC dynamic and microbial-mediated $C$ transformation to better forecast soil $\mathrm{C}$ dynamics in regions with changing environments.

\section{Acknowledgments}

This work was supported by the National Natural Science Foundation of China (41971119, 41871089), the Natural Science Foundation of Shandong Province (ZR2020QD004, ZR2019MD024), the Youth Innovation and Technology Foundation of Shandong Higher Education Institutions (2019KJD010).

\section{Electronic supplementary material}

Supplementary material is available in the online version of this article at https://doi.org/10.1007/s42832-021-0118-y and is accessible for authorized users.

\section{References}

Angst, G., Mueller, K.E., Nierop, K.G.J., Simpson, M.J., 2021. Plantor microbial-derived? A review on the molecular composition of stabilized soil organic matter. Soil Biology \& Biochemistry 156, 108189.

Chen, J., Wang, H., Hu, G., Li, X., Dong, Y., Zhuge, Y., He, H., Zhang, $X ., 2021$. Distinct accumulation of bacterial and fungal residues along a salinity gradient in coastal salt-affected soils. Soil Biology and Biochemistry 158, 108266

Chi, Y., Shi, H., Zheng, W., Sun, J., 2018. Simulating spatial distribution of coastal soil carbon content using a comprehensive land surface factor system based on remote sensing. Science of the Total Environment 628-629, 384-399.

Chi, Y., Sun, J., Liu, W., Wang, J., Zhao, M., 2019. Mapping coastal wetland soil salinity in different seasons using an improved comprehensive land surface factor system. Ecological Indicators 107, 105517.

Cho, K.H., Beon, M.S., Jeong, J.C., 2018. Dynamics of soil salinity and vegetation in a reclaimed area in Saemangeum, Republic of Korea. Geoderma 321, 42-51.

Chu, X., Han, G., Xing, Q., Xia, J., Sun, B., Li, X., Yu, J., Li, D., Song, W., 2019. Changes in plant biomass induced by soil moisture variability drive interannual variation in the net ecosystem $\mathrm{CO}_{2}$ exchange over a reclaimed coastal wetland. Agricultural and 
Forest Meteorology 264, 138-148.

Dalal, R., 1998. Soil microbial biomass - what do the numbers really mean? Australian Journal of Experimental Agriculture 38, 649 665.

Engelking, B., Flessa, H., Joergensen, R.G., 2007. Shifts in amino sugar and ergosterol contents after addition of sucrose and cellulose to soil. Soil Biology \& Biochemistry 39, 2111-2118.

Fang, Y., Nazaries, L., Singh, B.K., Singh, B.P., 2018. Microbial mechanisms of carbon priming effects revealed during the interaction of crop residue and nutrient inputs in contrasting soils. Global Change Biology 24, 2775-2790.

Fu, H., Jian, X., Zhang, W., Shang, F., 2020. A comparative study of methods for determining carbonate content in marine and terrestrial sediments. Marine and Petroleum Geology 116, 104337.

Groshans, G.R., Mikhailova, E., Post, C., Schlautman, M., 2018. Accounting for soil inorganic carbon in the ecosystem services framework for United Nations sustainable development goals. Geoderma 324, 37-46.

Hessini, K., Issaoui, K., Ferchichi, S., Saif, T., Abdelly, C., Siddique, K. H., Cruz, C., 2019. Interactive effects of salinity and nitrogen forms on plant growth, photosynthesis and osmotic adjustment in maize. Plant Physiology and Biochemistry 139, 171-178.

Hu, G.Q., Liu, X., He, H.B., Chen, W.F., Zhuge, Y.P., Dong, Y.J., Wang $\mathrm{H}$., 2018. Accumulation characteristics of amino sugars in salinized soils of different types in the Yellow River Delta. Turang Xuebao 55, 390-398 (In Chinese).

Huber, D.P., Lohse, K.A., Commendador, A., Joy, S., Aho, K., Finney, B., Germino, M.J., 2019. Vegetation and precipitation shifts interact to alter organic and inorganic carbon storage in cold desert soils. Ecosphere 10, e02655.

Kögel-Knabner, I., 2017. The macromolecular organic composition of plant and microbial residues as inputs to soil organic matter: fourteen years on. Soil Biology \& Biochemistry 105, A3-A8.

Lal, R., Kimble, J., Stewart, B A; Eswaran, H, 2000. Global Climate Change and Pedogenic Carbonates, Lewis Publishers, Boca Raton, USA pp.1-14.

Le Quéré, C., Andrew, R.M., Friedlingstein, P., Sitch, S., Hauck, J. Pongratz, J., Pickers, P.A., Korsbakken, J.I., Peters, G.P., Canadell, J.G., Arneth, A., Arora, V.K., Barbero, L., Bastos, A., Bopp, L., Chevallier, F., Chini, L.P., Ciais, P., Doney, S.C., Gkritzalis, T., Goll, D.S., Harris, I., Haverd, V., Hoffman, F.M., Hoppema, M., Houghton, R.A., Hurtt, G., Ilyina, T., Jain, A.K., Johannessen, T., Jones, C.D., Kato, E., Keeling, R.F., Goldewijk, K.K., Landschützer, P., Lefèvre, N., Lienert, S., Liu, Z., Lombardozzi, D., Metzl, N., Munro, D.R., Nabel, J.E.M.S., Nakaoka, S., Neill, C., Olsen, A., Ono, T., Patra, P., Peregon, A., Peters, W., Peylin, P., Pfeil, B., Pierrot, D., Poulter, B., Rehder, G., Resplandy, L., Robertson, E., Rocher, M., Rödenbeck, C., Schuster, U., Schwinger, J., Séférian, R., Skjelvan, I., Steinhoff, T., Sutton, A., Tans, P.P., Tian, H., Tilbrook, B., Tubiello, F.N., van der LaanLuijkx, I.T., van der Werf, G.R., Viovy, N., Walker, A.P., Wiltshire, A. J., Wright, R., Zaehle, S., Zheng, B., 2018. Global carbon budget 2018. Earth System Science Data 10, 2141-2194.

Lehmann, J., Hansel, C.M., Kaiser, C., Kleber, M., Maher, K. Manzoni, S., Nunan, N., Reichstein, M., Schimel, J.P., Torn, M. S., Wieder, W.R., Kögel-Knabner, I., 2020. Persistence of soil organic carbon caused by functional complexity. Nature Geoscience 13, 529-534.

Lian, B., Chen, Y., Tang, Y., 2010. Microbes on carbonate rocks and pedogenesis in karst regions. Journal of Earth Science 21, 293296.

Liang, C., 2020. Soil microbial carbon pump: Mechanism and appraisal. Soil Ecology Letters 2, 241-254.

Liang, C., Amelung, W., Lehmann, J., Kästner, M., 2019. Quantitative assessment of microbial necromass contribution to soil organic matter. Global Change Biology 25, 3578-3590.

Liang, C., Kästner, M., Joergensen, R.G., 2020. Microbial necromass on the rise: the growing focus on its role in soil organic matter development. Soil Biology \& Biochemistry 150, 108000.

Liang, C., Schimel, J.P., Jastrow, J.D., 2017. The importance of anabolism in microbial control over soil carbon storage. Nature Microbiology 2, 1-6.

Liu, X.J.A., Finley, B.K., Mau, R.L., Schwartz, E., Dijkstra, P., Bowker, M.A., Hungate, B.A., 2020a. The soil priming effect: Consistent across ecosystems, elusive mechanisms. Soil Biology \& Biochemistry $140,107617$.

Liu, Z., Sun, Y., Zhang, Y., Qin, S., Sun, Y., Mao, H., Miao, L., 2020 b. Desert soil sequesters atmospheric $\mathrm{CO}_{2}$ by microbial mineral formation. Geoderma 361, 114104.

Ma, Z., Zhang, M., Xiao, R., Cui, Y., Yu, F., 2017. Changes in soil microbial biomass and community composition in coastal wetlands affected by restoration projects in a Chinese delta. Geoderma 289, 124-134.

Mi, N., Wang, S., Liu, J., Yu, G., Zhang, W., Jobbagy, E., 2008. Soil inorganic carbon storage pattern in China. Global Change Biology 14, 2380-2387.

Miltner, A., Richnow, H.H., Kopinke, F.D., Kästner, M., 2004. Assimilation of $\mathrm{CO}_{2}$ by soil microorganisms and transformation into soil organic matter. Organic Geochemistry 35, 1015-1024.

Moore, K.A., Altus, S., Tay, J.W., Meehl, J.B., Johnson, E.B., Bortz, D. M., Cameron, J.C., 2020. Mechanical regulation of photosynthesis in cyanobacteria. Nature Microbiology 5, 757-767.

Munns, R., Passioura, J.B., Colmer, T.D., Byrt, C.S., 2020. Osmotic adjustment and energy limitations to plant growth in saline soil. New Phytologist 225, 1091-1096.

Perez, R.C., Matin, A., 1982. Carbon dioxide assimilation by Thiobacillus novellus under nutrient-limited mixotrophic conditions. Journal of Bacteriology 150, 46-51.

Prommer, J., Walker, T.W., Wanek, W., Braun, J., Zezula, D., Hu, Y., Hofhansl, F., Richter, A., 2020. Increased microbial growth, biomass, and turnover drive soil organic carbon accumulation at higher plant diversity. Global Change Biology 26, 669-681.

Raheb, A., Heidari, A., Mahmoodi, S., 2017. Organic and inorganic carbon storage in soils along an arid to dry sub-humid climosequence in northwest of Iran. Catena 153, 66-74.

Rath, K.M., Murphy, D.N., Rousk, J., 2019. The microbial community size, structure, and process rates along natural gradients of soil salinity. Soil Biology \& Biochemistry 138, 107607.

Raza, S., Miao, N., Wang, P., Ju, X., Chen, Z., Zhou, J., Kuzyakov, Y., 2020. Dramatic loss of inorganic carbon by nitrogen-induced soil acidification in Chinese croplands. Global Change Biology 26, 3738-3751. 
Rowley, M.C., Grand, S., Adatte, T., Verrecchia, E.P., 2020. A cascading influence of calcium carbonate on the biogeochemistry and pedogenic trajectories of subalpine soils, Switzerland. Geoderma 361, 114065.

Schmidt, M.W.I., Torn, M.S., Abiven, S., Dittmar, T., Guggenberger, G., Janssens, I.A., Kleber, M., Köegel-Knabner, I., Lehmann, J., Manning, D.A.C., Nannipieri, P., Rasse, D.P., Weiner, S., Trumbore, S.E., 2011. Persistence of soil organic matter as an ecosystem property. Nature 478, 49-56.

Shao, P., Lynch, L., Xie, H., Bao, X., Liang, C., 2021. Tradeoffs among microbial life history strategies influence the fate of microbial residues in subtropical forest soils. Soil Biology \& Biochemistry 153, 108112.

Wang, H., Wang, R., Yu, Y., Mitchell, M.J., Zhang, L., 2011. Soil organic carbon of degraded wetlands treated with freshwater in the Yellow River Delta, China. Journal of Environmental Management 92, 2628-2633.

Wang, X., Jiang, Z., Li, Y., Kong, F., Xi, M., 2019. Inorganic carbon sequestration and its mechanism of coastal saline-alkali wetlands in Jiaozhou Bay, China. Geoderma 351, 221-234.

Wong, V.N., Greene, R., Dalal, R.C., Murphy, B.W., 2010. Soil carbon dynamics in saline and sodic soils: a review. Soil Use and Management 26, 2-11.

Xia, J., Ren, J., Zhang, S., Wang, Y., Fang, Y., 2019. Forest and grass composite patterns improve the soil quality in the coastal salinealkali land of the Yellow River Delta, China. Geoderma 349, 25-35.

Xie, J., Li, Y., Zhai, C., Li, C., Lan, Z., 2009. $\mathrm{CO}_{2}$ absorption by alkaline soils and its implication to the global carbon cycle. Environmental Geology 56, 953-961.

Yin, L., Dijkstra, F.A., Wang, P., Zhu, B., Cheng, W., 2018. Rhizosphere priming effects on soil carbon and nitrogen dynamics among tree species with and without intraspecific competition.
New Phytologist 218, 1036-1048.

Zamanian, K., Pustovoytov, K., Kuzyakov, Y., 2016. Pedogenic carbonates: Forms and formation processes. Earth-Science Reviews 157, 1-17.

Zamanian, K., Zhou, J., Kuzyakov, Y., 2021. Soil carbonates: The unaccounted, irrecoverable carbon source. Geoderma 384, 114817.

Zhang, G., Bai, J., Tebbe, C.C., Zhao, Q., Jia, J., Wang, W., Wang, X., $\mathrm{Yu}, \mathrm{L}$., 2021a. Salinity controls soil microbial community structure and function in coastal estuarine wetlands. Environmental Microbiology 23, 1020-1037.

Zhang, K., Wang, X., Wu, L., Lu, T., Guo, Y., Ding, X., 2021b. Impacts of salinity on the stability of soil organic carbon in the croplands of the Yellow River Delta. Land Degradation \& Development 32, 1873-1882.

Zhang, X., Amelung, W., 1996. Gas chromatographic determination of muramic acid, glucosamine, mannosamine, and galactosamine in soils. Soil Biology \& Biochemistry 28, 1201-1206.

Zhao, Q., Bai, J., Gao, Y., Zhao, H., Zhang, G., Cui, B., 2020a. Shifts in the soil bacterial community along a salinity gradient in the Yellow River Delta. Land Degradation \& Development 31, 2255-2267.

Zhao, X., Zhao, C., Stahr, K., Kuzyakov, Y., Wei, X., 2020b. The effect of microorganisms on soil carbonate recrystallization and abiotic $\mathrm{CO}_{2}$ uptake of soil. Catena 192, 104592.

Zhu, C., Ling, N., Li, L., Liu, X., Dippold, M.A., Zhang, X., Guo, S., Kuzyakov, Y., Shen, Q., 2020. Compositional variations of active autotrophic bacteria in paddy soils with elevated $\mathrm{CO}_{2}$ and temperature. Soil Ecology Letters 2, 295-307.

Zhu, X., Jackson, R.D., Delucia, E.H., Tiedje, J.M., Liang, C., 2020. The soil microbial carbon pump: from conceptual insights to empirical assessments. Global Change Biology 26, 6032-6039. 